Original Research Article

\title{
Evaluation of losartan plus hydrochlorothiazide combination therapy against amlodipine monotherapy in patients of hypertension
}

\author{
Swati D. Sawant ${ }^{1}$, Sanjeevani M. Chawre ${ }^{2 *}$, Kalpana S. Dudhal ${ }^{3}$, Amit A. Bansode ${ }^{4}$
}

\begin{abstract}
${ }^{1}$ Department of Biochemistry, ${ }^{4}$ Department of Pharmacology, Dr. V. M. G. M. C., Solapur, Maharashtra, India ${ }^{2}$ Department of Pharmacology, D.Y. Patil Medical College and Hospital, Pune, Maharashtra, India

${ }^{3}$ Department of Pharmacology, Lokmanya Tilak Municipal Medical College, Sion, Mumbai, Maharashtra, India
\end{abstract}

Received: 10 September 2019

Revised: 10 October 2019

Accepted: 12 October2019

*Correspondence to:

Dr. Sanjeevani M. Chawre,

Email: dr.sanjeevani1802@ gmail.com

Copyright: (C) the author(s), publisher and licensee Medip Academy. This is an openaccess article distributed under the terms of the Creative Commons Attribution NonCommercial License, which permits unrestricted noncommercial use, distribution, and reproduction in any medium, provided the original work is properly cited.

\begin{abstract}
Background: Microalbuminuria has been shown to predict cardiovascular disease (CVD) in patients with hypertension. Recently the FDC of losartan and hydrochlorothiazide (HCTZ) has been reported to be effective for achieving a target BP level and also improvement in cardiovascular prognosis. The present study was conducted to compare effect of losartan plus hydrochlorothiazide combination therapy and high dose amlodipine monotherapy on blood pressure and microalbuminuria.

Methods: Total 184 patients with hypertension were randomly allocated to two groups. The patients in group 1 received Amlodipine $5 \mathrm{mg}$ orally for first 4 weeks. The patients from group 2 received losartan $50 \mathrm{mg}$ orally for first 4 weeks. Patients in group 1 were titrated to amlodipine $10 \mathrm{mg}$ orally for next 4 weeks. The patients in group 2 were titrated to FDC of losartan $(50 \mathrm{mg})$ plus HCTZ (12.5 mg) for next 4 weeks. Follow-up visits were scheduled at 4 weeks and 8 weeks. Pulse rate, sSBP and sDBP were estimated at each followup. Microalbuminuria was estimated at 8 weeks.

Results: There was no significant difference in mean change in sSBP, sDBP and pulse rate between two treatment groups $(p>0.05)$. There was greater reduction in microalbuminuria in group 2 patients $(\mathrm{p}<0.0001)$. The adverse effects such as flushing and lower extremity oedema were significantly more in amlodipine group $(\mathrm{p}<0.05)$.

Conclusions: Losartan plus HCTZ has similar effect on BP, better safety profile and superior effect on microalbuminuria level reduction.
\end{abstract}

Keywords: Microalbuminuria, Losartan plus hydrochorothiazide, Amlodipine, Blood pressure

\section{INTRODUCTION}

Hypertension is one of leading causes of global burden of disease resulting in 7.6 million deaths $(13-15 \%$ of total) and 92 million disability adjusted life years worldwide. ${ }^{1}$ Hypertension (HTN) is well recognized as independent, dominant, modifiable risk factor for cardiovascular events such as myocardial infarction (MI), congestive heart failure $(\mathrm{CHF})$, and end-stage renal disease. ${ }^{2}$ Strict blood pressure (BP) control has been shown to be associated with improved cardiovascular prognosis. ${ }^{3}$ Microalbuminuria is a marker of systemic inflammation and endothelial dysfunction and has been shown to predict cardiovascular disease (CVD) in patients with hypertension. ${ }^{4}$

Losartan is specific angiotensin II type 1 receptor (AT -1) antagonist. It has dose dependent anti-hypertensive effect 
which has been demonstrated in experimental and clinical studies. ${ }^{5}$ Recently the fixed dose combination of losartan and hydrochlorothiazide (HCTZ) has been reported to be effective for achieving a target BP level and also found to be effective in improvement in cardiovascular prognosis. ${ }^{6-8}$ Furthermore, it was also reported that addition of diuretics on RAAS inhibitor provided favourable effect for reduction of microalbuminuria. ${ }^{9}$ Amlodipine is a calcium channel blocker routinely used for the treatment of hypertension in our hospital. It has a strong BP lowering effect throughout 24 hour period. ${ }^{10}$ Furthermore, it has been reported that high dose amlodipine provided target organ protection. ${ }^{11}$ Long term treatment with amlodipine was effective in reducing urine albumin excretion (UAE) rate in hypertensive patients with type II diabetes and microalbuminuria. ${ }^{12}$ Very few studies in India have compared the effect of these drugs on microalbuminuria. So, the present study was conducted to compare effect of losartan plus hydrochlorothiazide combination therapy and high dose amlodipine monotherapy on blood pressure and microalbuminuria.

\section{METHODS}

This prospective, randomised, open labelled, 8 week study was conducted from January 2013 to January 2014 at Medicine Department of civil hospital attached to Government Medical College, Solapur after approval from institutional ethics committee.

\section{Inclusion criteria and exclusion criteria}

Men and women with age $\geq 20$ years with newly diagnosed hypertension (according to JNC VII) and willing to give informed consent were included in the study. ${ }^{13}$ The diagnosis of hypertension was done by a senior physician present on duty based on clinic blood pressure (BP) measurement defined as an average sitting systolic blood pressure (sSBP) of $140 \mathrm{~mm}$ of $\mathrm{Hg}$ or higher and sitting diastolic blood pressure (sDBP) of $90 \mathrm{~mm}$ of $\mathrm{Hg}$ or higher at one to three minute intervals on two or more different occasions using a mercury sphygmomanometer (Crown manometer 300, made in India). Sitting BP was measured after 5 minutes of rest in the seated position. Patients with sitting systolic BP ( $\mathrm{sSBP})>180 \mathrm{~mm}$ of $\mathrm{Hg}$ and sitting diastolic BP (sDBP) $>110 \mathrm{~mm}$ of $\mathrm{Hg}$ were excluded from the study. Patients with secondary HTN, diabetes, heart failure and allergy to study medication were also excluded from the study.

Sample size of 80 in each group was calculated by taking $\alpha$ (level of significance) $0.05, \beta$ as $0.1, \sigma_{1}$ (SD= standard deviation) is taken as 5.7; $\sigma_{2}$ is taken as 5.9 with allowable error 3.8 based on values of sDBP in previous study. ${ }^{14} 184$ patients fulfilling inclusion and exclusion criteria were randomised into two groups ( 92 patients in each group) using chit method. Baseline data such as pulse rate, blood pressure both $\mathrm{sSBP}$ and sDBP were recorded at the time of enrolment of patients ( 0 week). A baseline investigation such as microalbuminuria was done at the time of enrolment ( 0 week). All the data was recorded on a carefully designed proforma.

The patients in group 1 received Amlodipine $5 \mathrm{mg}$ single dose orally for first 4 weeks. The patients from group 2 received Losartan $50 \mathrm{mg}$ single dose orally for first 4 weeks. During the first 4 week treatment period, if a marked BP reduction was obtained which was defined as $\mathrm{BP}$ reduction of $\geq 30 \mathrm{~mm}$ of $\mathrm{Hg}$ in $\mathrm{sSBP}$ or $\mathrm{sDBP}$ with simultaneous achievement of target BP i.e BP $\leq 140 / 90$ $\mathrm{mm}$ of $\mathrm{Hg}$ after monotherapy, further dose titration was stopped. However, these patients were also included in the analysis of results.

After 4 week, patients in group 1 were titrated to Amlodipine $10 \mathrm{mg}$ single dose orally for next 4 weeks. The patients in group 2 were titrated to fixed dose combination of Losartan (50 mg) plus hydrochlorothiaizide $(12.5 \mathrm{mg})$ for next 4 weeks.

Follow-up visits were scheduled at 4 weeks and 8 weeks. Pulse rate, sSBP and SDBP were estimated at each follow-up. At 8 weeks, microalbuminuria was estimated in all patients from both groups. During each follow-up, patients were interviewed and examined for occurrence any adverse effects.

\section{Efficacy end points}

The primary efficacy end points were mean changes in sSBP, sDBP and microalbuminuria levels from baseline to final assessment i.e. at 8 weeks. Along with it, the secondary efficacy end point included the mean change in pulse rate from baseline to final assessment.

Response rate defined as the percentage of patients who achieved sSBP target of $\leq 140 \mathrm{~mm}$ of $\mathrm{Hg}$ at 4 weeks and 8 weeks of treatment was calculated.

\section{Safety and tolerability measures}

At each visit, patients were interviewed for occurrence of any adverse effects and physically examined during the study period.

Microalbuminuria analysis was done on first morning void urine samples at central Biochemistry Laboratory of the hospital. Microalbuminuria was measured by enzymatic method using pyrogallol red- molybdate complex. $^{15}$

\section{Statistical analysis}

Unpaired ' $\mathrm{t}$ ' test and ' $\mathrm{z}$ ' test for difference between two proportions were used respectively to analyse continuous and categorical characteristics at baseline. Efficacy end points in both treatment groups were analysed by paired ' $t$ ' test. Efficacy end points between two treatment groups were analysed by unpaired ' $t$ ' test. Safety end points in 
both treatment groups were analysed by ' $z$ ' test for difference between two proportions. $\mathrm{P}<0.05$ was considered statistically significant.

\section{RESULTS}

In the present study, 6 patients from amlodipine group and 2 patients from losartan plus hydrochlorothiazide group were lost to follow up. Thus 86 patients from amlodipine group and 90 patients from losartan plus hydrochlorothiazide group were analysed statistically.

At the start of the study, both the groups were comparable as regard to age, sex distribution, weight, sSBP, sDBP, pulse rate and microalbuminuria as there was no statistically significant difference between the two groups $(\mathrm{p}>0.05)$ (Table 1).

Table 1: Baseline characteristics of the study population.

\begin{tabular}{|llll|}
\hline Variable & $\begin{array}{l}\text { Amlodipine group } \\
(\mathbf{n = 8 6})\end{array}$ & $\begin{array}{l}\text { Losartan plus } \\
\text { hydrochlorothiazide group }(\mathbf{n = 9 0 )}\end{array}$ & \begin{tabular}{c} 
P value \\
\hline Age (years)*
\end{tabular} \\
\hline Gender \# & $52.98 \pm 6.51$ & $51.83 \pm 7.80$ & $>0.05$ \\
\hline Male & $48(55.81 \%)$ & $46(51.11 \%)$ & $>0.05$ \\
\hline Female & $38(44.18 \%)$ & $44(48.88 \%)$ & $>0.05$ \\
\hline Weight (in Kgs)* & $63.75 \pm 6.30$ & $62.93 \pm 8.36$ & $>05$ \\
\hline Blood pressure (BP)* & & & $>0.05$ \\
\hline sSBP & $160.62 \pm 10.04$ & $160.48 \pm 9.91$ & $>0.05$ \\
\hline sDBP & $100.97 \pm 5.37$ & $100.86 \pm 5.28$ & $>0.05$ \\
\hline Pulse rate (bpm)* & $73.90 \pm 4.48$ & $73.389 \pm 3.69$ & $>0.05$ \\
\hline Microalbuminuria (mg/L) ${ }^{*}$ & $112.97 \pm 46.35$ & $113.04 \pm 49.46$ & \\
\hline
\end{tabular}

(sSBP: sitting systolic BP, sDBP: sitting diastolic BP, bpm: beats per minute); (*: unpaired t test; \#: ' $\mathrm{z}$ ' test between two proportions)

Table 2: Changes in mean values of sSBP and sDBP in amlodipine group.

\begin{tabular}{|llll|}
\hline Parameter & Baseline & 4 week & 8 week \\
\hline SSBP $(\mathbf{m m}$ of $\mathbf{H g})$ & $160.62 \pm 10.04$ & $150.46 \pm 10.39 *$ & $143.44 \pm 7.54 *$ \\
\hline SDBP $(\mathbf{m m}$ of $\mathbf{H g})$ & $100.97 \pm 5.37$ & $96.04 \pm 4.76^{*}$ & $89.76 \pm 1.71 *$ \\
\hline
\end{tabular}

$* \mathrm{p}<0.0001$; (paired't' test).

Table 3: Changes in mean values of sSBP and SDBP in losartan plus hydrochlorothiazide group.

\begin{tabular}{|llll|}
\hline Parameter & Baseline & 4 weeks & 8 weeks \\
\hline SSBP $(\mathbf{m m}$ of $\mathbf{H g})$ & $160.48 \pm 9.91$ & $151.06 \pm 7.69^{*}$ & $143.64 \pm 6.28^{*}$ \\
\hline SDBP $(\mathbf{m m}$ of $\mathbf{H g})$ & $100.86 \pm 4.69$ & $96.17 \pm 3.81^{*}$ & $89.8 \pm 2.45^{*}$ \\
\hline
\end{tabular}

*p $<0.0001$; (paired 't' test)

Table 4: Mean change in levels of $\mathrm{SSBP}(\mathrm{mm}$ of $\mathrm{Hg})$ in both treatment groups.

\begin{tabular}{|llll|}
\hline Duration of study & $\begin{array}{l}\text { Amlodipine group } \\
(\mathbf{n = 8 6})\end{array}$ & $\begin{array}{l}\text { Losartan plus } \\
\text { hydrochlorothiazide group } \\
(\mathbf{n = 9 0 )}\end{array}$ & P value \\
\hline 4 week & $150.46 \pm 10.39$ & $151.06 \pm 7.69$ & $>0.05$ \\
\hline 8 week & $143.44 \pm 7.55$ & $143.64 \pm 6.28$ & $>0.05$ \\
\hline
\end{tabular}

(unpaired 't' test)

Table 5: Mean change in levels of $\mathrm{SDBP}(\mathrm{mm}$ of $\mathrm{Hg})$ in both treatment groups.

\begin{tabular}{|llll|}
\hline Duration of study & $\begin{array}{l}\text { Amlodipine group } \\
(\mathbf{n = 8 6 )}\end{array}$ & $\begin{array}{l}\text { Losartan plus } \\
\text { hydrochlorothiazide group } \\
(\mathbf{n = 9 0 )}\end{array}$ & P value \\
\hline 4 weeks & $96.04 \pm 4.76$ & $96.18 \pm 3.81$ & $>0.05$ \\
\hline 8 weeks & $89.76 \pm 1.72$ & $89.8 \pm 2.45$ & $>0.05$ \\
\hline
\end{tabular}

(unpaired 't' test) 
In amlodipine group, sSBP was significantly reduced by $10.16 \mathrm{~mm}$ of $\mathrm{Hg}$ and by $17.18 \mathrm{~mm}$ of $\mathrm{Hg}$ at 4 and 8 weeks respectively when compared to baseline $(\mathrm{p}<0.0001)$. sDBP was also significantly reduced by $4.93 \mathrm{~mm}$ of $\mathrm{Hg}$ and by $11.21 \mathrm{~mm}$ of $\mathrm{Hg}$ at 4 and 8 weeks respectively when compared to baseline $(\mathrm{p}<0.0001)$ (Table 2$)$.

In losartan plus hydrochlorothiazide group, sSBP was significantly reduced by $9.42 \mathrm{~mm}$ of $\mathrm{Hg}$ and by $16.84 \mathrm{~mm}$ of $\mathrm{Hg}$ at 4 and 8 weeks respectively when compared to baseline $(\mathrm{p}<0.0001)$. sDBP was also significantly reduced by $4.69 \mathrm{~mm}$ of $\mathrm{Hg}$ and $11.06 \mathrm{~mm}$ of $\mathrm{Hg}$ at 4 and 8 weeks respectively when compared to baseline $(p<0.0001)$ (Table 3 ). There was no significant difference in mean change of sSBP and sDBP at 4 weeks and 8 weeks between the two treatment groups $(\mathrm{p}>0.05)$ (Table 4 and $5)$.

There was greater reduction in levels of microalbuminuria in losartan plus hydrochlorothiazide group as compared to those patients in amlodipine group at 8 weeks. This difference in mean change of microalbuminuria in two treatment groups was highly significant at 8 weeks $(\mathrm{p}<0.0001)$ (Figure 1).

Table 6: Percentage of patients who achieved sSBP goal of $\leq 140 \mathrm{~mm}$ of $\mathrm{Hg}$ at 4 weeks and at 8 weeks in two treatment groups.

\begin{tabular}{|llll|}
\hline Duration of study & $\begin{array}{l}\text { Amlodipine group } \\
(\mathbf{n = 8 6})\end{array}$ & $\begin{array}{l}\text { Losartan plus } \\
\text { hydrochlorothiazide }(\mathbf{n = 9 0})\end{array}$ & P value \\
\hline $\mathbf{4}$ week & $4.65 \%(4 / 86)$ & $4.44 \%(4 / 90)$ & $>0.05$ \\
\hline $\mathbf{8}$ week & $59.30 \%(51 / 86)$ & $55.56 \%(50 / 90)$ & $>0.05$ \\
\hline
\end{tabular}

Unpaired 't' test

Table 7: Changes in mean values of pulse rate in amlodipine group.

\begin{tabular}{|lllc|}
\hline Parameter & Baseline & 4 week & 8 week \\
\hline Pulse rate (beats/min) & $73.90 \pm 4.48$ & $75.09 \pm 4.43^{*}$ & $80.83 \pm 3.95 * *$ \\
\hline${ }^{*}<0.05 ; * * p<0.0001 ;$ (paired 't' test) & & &
\end{tabular}

Table 8: Changes in mean values of pulse rate in losartan plus hydrochlorothiazide group.

\begin{tabular}{|lllc|}
\hline Parameter & Baseline & 4 week & 8 week \\
\hline Pulse rate (beats / min) & $73.38 \pm 3.69$ & $73.63 \pm 4.01$ & $80.86 \pm 3.93^{*}$ \\
\hline
\end{tabular}

$* \mathrm{p}<0.0001$; (paired ' $\mathrm{t}$ ' test)

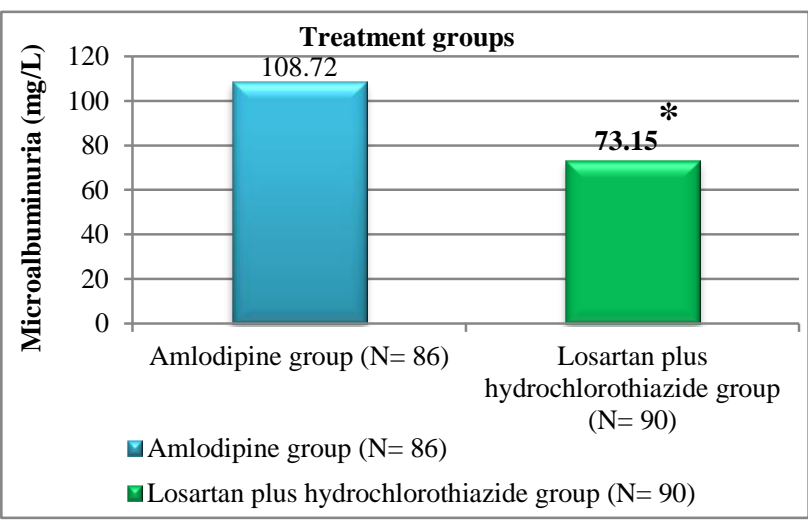

Figure 1: Mean change in levels of microalbuminuria $(\mathrm{mg} / \mathrm{l})$ in both treatment groups at end of the study i.e. 8 weeks.

$*(\mathrm{p}<0.0001)$; (unpaired 't' test)

Response rate i.e. percentage of patients who achieved sSBP goal of $\leq 140 \mathrm{~mm}$ of $\mathrm{Hg}$ was $4.65 \%$ and $4.44 \%$ in amlodipine group and losartan plus hydrochlorothiazide group respectively at 4 weeks of the study. At the end of study, response rate was higher in amlodipine group (59.30\%) as compared to losartan plus hydrochlorothiazide group $(55.56 \%)$. The difference between response rates was not statistically significant at 4 weeks and 8 weeks between two groups ( $>0.05)$ (Table 6).

Pulse rate was increased in amlodipine group as compared to baseline at 4 weeks $(\mathrm{p}<0.05)$ and 8 weeks $(\mathrm{p}<0.0001)$ (Table 7). In losartan plus hydrochlorothiazide group, pulse rate was increased numerically when compared to baseline at 4 week which was not statistically significant ( $p>0.05)$. However, at 8 weeks pulse rate was significantly increased by 7.23 beats/ min when compared to baseline in losartan plus hydrochlorothiazide group $(\mathrm{p}<0.0001)$ (Table 8). At 4 week, mean change in pulse rate in patients of amlodipine group was significantly higher than mean change in pulse rate in patients of losartan plus hydrochlorothiazide group $(\mathrm{p}<0.05)$. There was no significant difference in mean changes of pulse rate between two treatment groups at 8 weeks $(\mathrm{p}>0.05)$ (Figure 2).

There was no occurrence of any serious adverse event in any patients during this study. Minor adverse effects in form of headache, fatigue, dizziness, cough, flushing, lower extremity oedema were encountered in both groups. Incidences of adverse effects such as flushing, lower extremity oedema were significantly high in patients of amlodipine group than in patients of losartan plus 
hydrochlorothiazide group $(\mathrm{p}<0.05)$. There was no significant difference in the incidences of adverse effects such as cough, headache, fatigue, and dizziness in two treatment groups $(\mathrm{p}>0.05)$ (Figure 3$)$.

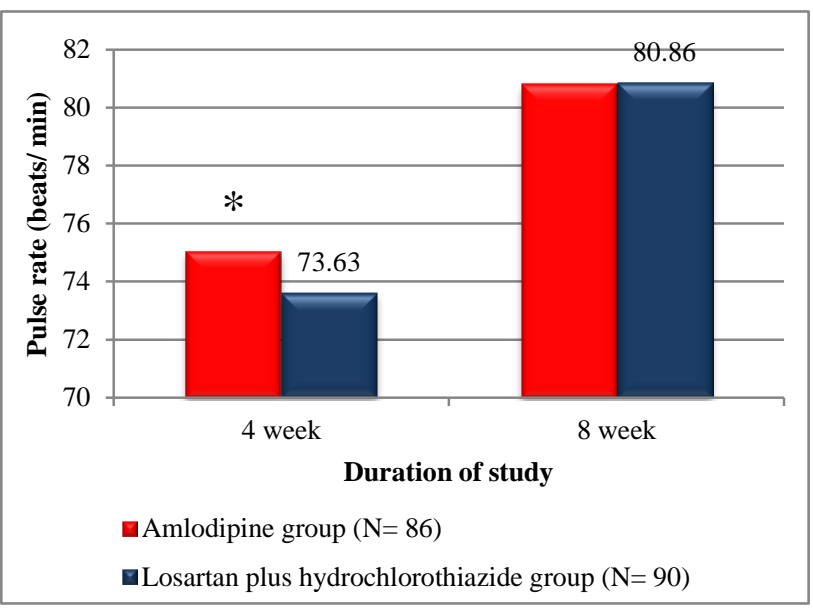

Figure 2: Mean changes in levels of pulse rate (beats/ min) in two treatment groups. $* \mathrm{p}<0.05$; unpaired ' $\mathrm{t}$ ' test.

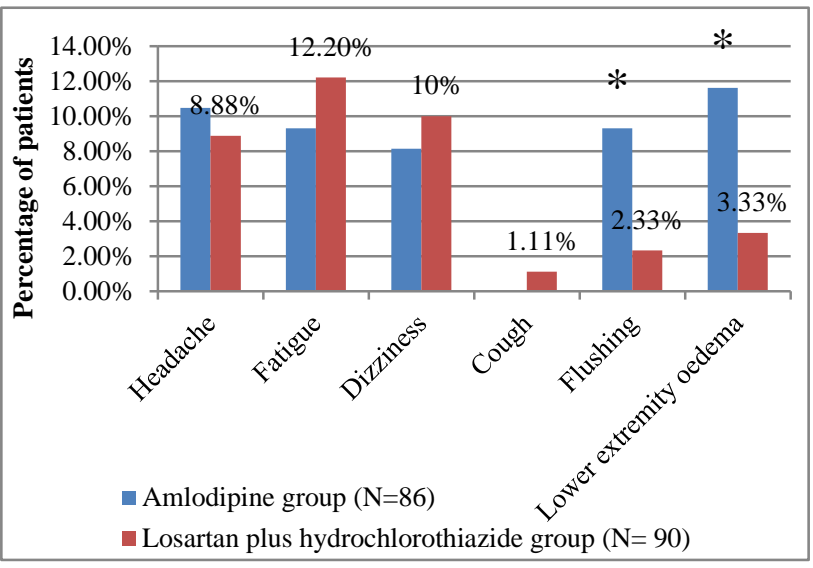

Figure 3: Incidence of adverse effects in both treatment groups.

*p<0.05; (' $z$ ' test between two proportions).

\section{DISCUSSION}

In the present prospective, randomised, open labelled study blood pressure lowering ability and tolerability of losartan plus hydrochlorothiazide (HCTZ) combination therapy was compared with that of amlodipine monotherapy in patients with hypertension.

The rationale for combining losartan, an angiotensin receptor blocker $(\mathrm{ARB})$ and $\mathrm{HCTZ}$, a thiazide diuretic is that these drugs have different mechanism of action, also combination will offset diuretic - induced increase in plasma renin activity. The salt loss will add to antihypertensive efficacy of losartan which is renin angiotensin aldosterone system (RAAS) blocker. Besides, an ARB will also attenuate the metabolic effects of thiazide diuretics like hypokalemia and hyperglycemia. ${ }^{16}$

We chose losartan in the dose of $50 \mathrm{mg}$ plus HCTZ in dose of $12.5 \mathrm{mg}$ as our study dose because it has been shown to be effective for treating hypertension and is not associated with any significant side effects. ${ }^{17,18}$ The dose of Amlodipine $10 \mathrm{mg}$ was selected as it is the standard dose used in our hospital for treatment of hypertension and the same dose was used in previous studies. ${ }^{19,20}$

In our study at the end of 8 weeks, we found that coadministration of losartan with HCTZ caused reduction in sitting systolic BP (sSBP) similar to amlodipine monotherapy. These findings are similar to those of Fukutomi et al, Chung et al, Wilson et al, Dahlof et al. $^{14,17,21,22}$

Losartan plus HCTZ combination therapy provided 16.84 $\mathrm{mm}$ of $\mathrm{Hg}$ of mean reduction in SSBP, amlodipine monotherapy provided $17.18 \mathrm{~mm}$ of $\mathrm{Hg}$ of mean reduction in SSBP. This difference in mean reduction of sSBP between two groups was not statistically significant ( $p>0.05)$. Some studies have demonstrated higher mean reduction of sSBP than that in our study. In the study by Volpe et al, investigators found that at the end of 18 weeks losartan plus HCTZ combination therapy resulted in $27.4 \mathrm{~mm}$ of $\mathrm{Hg}$ of mean reduction in SSBP as compared to $28.2 \mathrm{~mm}$ of $\mathrm{Hg}$ with Amlodipine monotherapy. ${ }^{23}$ Fukutomi et al reported a $22.2 \mathrm{~mm}$ of $\mathrm{Hg}$ of mean reduction in SSBP with losartan plus HCTZ combination therapy and $28.7 \mathrm{~mm}$ of $\mathrm{Hg}$ of mean reduction in SSBP with amlodipine monotherapy. ${ }^{17}$ Our findings however are in variance with Phillips et al where they had reported significantly higher reduction in sSBP with amlodipine monotherapy $(16.1 \mathrm{~mm}$ of $\mathrm{Hg}$ ) when compared with losartan with or without HCTZ combination therapy (13.7 $\mathrm{mm}$ of $\mathrm{Hg})(\mathrm{p}<0.05) .{ }^{18}$

Losartan plus HCTZ combination therapy provided 11.06 $\mathrm{mm}$ of $\mathrm{Hg}$ of mean reduction in SDBP and amlodipine monotherapy provided $11.21 \mathrm{~mm}$ of $\mathrm{Hg}$ of mean reduction in SDBP. This difference in mean reduction of sDBP between two groups was not statistically significant ( $p>0.05$ ). The mean reduction of $\mathrm{sDBP}$ by $11.06 \mathrm{~mm}$ of $\mathrm{Hg}$ in our study is similar to that of Chung et al where they had reported $11.6 \mathrm{~mm}$ of $\mathrm{Hg}$ of mean reduction in sDBP with combination therapy. ${ }^{21}$ Our findings are however in variance with Carlos et al where they had reported significantly higher reduction in sDBP with losartan plus HCTZ combination therapy $(18.1 \mathrm{~mm}$ od $\mathrm{Hg}$ ) when compared with amlodipine monotherapy (12.4 $\mathrm{mm}$ of $\mathrm{Hg} ; \mathrm{p}=0.009$ ) at the end of 12 weeks. ${ }^{19}$

In our study at the end of 8 weeks, we found that pulse rate was increased by 7.23 beats/min in losartan plus hydrochlorothiazide group and by 6.93 beats/min in amlodipine group. There was no significant difference between two groups with respect to change in pulse rate at 8 weeks $(p>0.05)$. 
In our study, $59.30 \%(51 / 86)$ of patients from amlodipine group and $55.56 \%$ (50/90) of patients from losartan plus HCTZ group achieved sSBP goal of $\leq 140 \mathrm{~mm}$ of $\mathrm{Hg}$ (as defined by JNC VII guidelines) at the end of study. The difference between the two treatment groups in the percentage of patients achieving JNC VII sSBP target was not significant $(p>0.05)$. Chung et al in their study reported similar findings. ${ }^{21}$ In the study by Volpe et al, at the end of 18 weeks $73.9 \%$ of patients from losartan plus HCTZ group achieved sSBP goal of $\leq 140 \mathrm{~mm}$ of $\mathrm{Hg}^{23}$ Higher response rate (defined as percentage of patients achieving sSBP goal of $\leq 140 \mathrm{~mm}$ of $\mathrm{Hg}$ ) in this study as compared to our study might be due to use of higher doses of losartan and HCTZ. They used losartan in doses of $50 \mathrm{mg}, 100 \mathrm{mg}$ and HCTZ in doses of $12.5 \mathrm{mg}, 25 \mathrm{mg}$.

At the end of 8 weeks of combination therapy with losartan plus HCTZ produced a significant reduction in levels of microalbuminuria when compared with baseline levels. However, amlodipine monotherapy after 8 weeks resulted in a slight reduction in levels of microalbuminuria which was not significant when compared with baseline levels. Microalbuminuria reduction was significantly more in patients receiving combination therapy than in patients receiving amlodipune monotherapy at end of study. This difference in microalbuminuria was found to be statistically significant $(p<0.0001)$. This finding is similar to study by fukutomi et al where they had reported $47.6 \%$ reduction in microalbuminuria levels with losartan plus HCTZ combination therapy as compared $2.4 \%$ increase in microalbuminuria level with amlodipine monotherapy $(p<0.001) .{ }^{17}$ This finding suggests that anti-albuminuric effects of losartan plus HCTZ combination are independent of BP lowering. Angiotensin converting enzyme inhibitors (ACEIs) and ARBs have been reported to reduce urine albumin creatinine ratio (UACR) through dilation of efferent glomerular arterioles and the reduction of glomerular capillary pressure. ${ }^{24}$ Therefore, superiority of microalbuminuria reduction in losartan plus HCTZ group may be due to losartan which is an angiotensin receptor blocker (ARB).

The combination of losartan plus HCTZ and amlodipine monotherapy was well tolerated. The most commonly noted adverse effects were headache, fatigue, dizziness. The adverse effects such as flushing and lower extremity oedema were significantly more in patients receiving amlodipine monotherapy than in patients receiving combination therapy with losartan and HCTZ $(\mathrm{p}<0.05)$. Our findings are consistent with the study by Volpe et al. ${ }^{23}$ The probable mechanism of flushing and lower extremity oedema in amlodipine group might be its peripheral vasodilating property. The adverse events were mild and none of the patients from either group discontinued the study drugs because of it.

\section{CONCLUSION}

The results of the present study demonstrate that both groups have similar effect on BP, whereas combination therapy has superior effect on microalbuminuria level reduction. This superiority of losartan plus HCTZ combination therapy on microalbuminuria reduction might lead to decrease in future cardiovascular risks. However, further long term studies are required to establish its efficacy in reducing future cardiovascular risks. This combination therapy is well tolerated as compared to amlodipine monotherapy. Hence, combination therapy of losartan plus HCTZ can be considered as a better alternative to Amlodipine monotherapy for the treatment of hypertension.

\section{Funding: No funding sources}

Conflict of interest: None declared

Ethical approval: The study was approved by the Institutional Ethics Committee

\section{REFERENCES}

1. Kotchen TA. Hypertensive vascular disease. In: Lango DL, Fauci AS, Kasper DL, Hauser SL, Jameson JL, Loscalzo J, eds. Harrison's principle of Internal Medicine, $18^{\text {th }}$ edition, McGraw Hill, New York; 2012: 1688-1705.

2. Marma AK, Lloyd- Jones DM. Systemic examination of the updated Framingham heart study general cardiovascular risk profile. Circulation. 2009;120:384-90.

3. Chrysant SG, Chrysant GS. Effectiveness of lowering $\mathrm{BP}$ to prevent stroke versus to prevent coronary events. Am J Cardiol. 2010;106:825-9.

4. Parving HH. Microalbuminuria in essential hypertension and diabetes mellitus. J Hypertens Suppl. 1996;14(2):S89-93.

5. Kavagaci H, Sahin A, Ozdemir F. The effects of losartan \& fosinopril in hypertensive type 2 diabetic patients. Diabetic Res Clin Pract. 2002;58:19-25.

6. Saruta T, Ogihara T, Matsuoka H, Suzuki H, Toki M, Hirayama Y, et al. Antihypertensive efficacy \& safety of fixed-dose combination therapy with losartan plus hydrochlorothiazide in japanese patients with essential hypertension. Hypertens Res. 2007;30:729-39.

7. Oparil S, Abate N, Chen E, Creager MA, Galet V, Jia $\mathrm{G}$, et al. A double-blind, randomized study evaluating losartan potassium monotherapy or in combination with hydrochlorothiazide vesus placebo in obese patients with hypertension. Curr Med Res Opin. 2008;24:1101-14.

8. Dahlof B, Devereux RB, Kjedsen SE, Julius S, Beevers G, de Faire U, et al. Cardiovascular morbidity in the Losartan Intervention for Endpoint Reduction in Hypertension study (LIFE): a randomized trial against atenolol. Lancet. 2002;359(9311):995-1003. 
9. Bakris GL, Toto RD, McCullough PA, Rocha R, Purkayastha D, Davis P. Effects of different ACE inhibitor combinations on albuminuria: results of the GUARD study. Kidney Int. 2008;73:1303-9.

10. Eguchi K, Kario K, Hoshide Y, Hoshide S, Ishikawa $\mathrm{J}$, Morinari $\mathrm{M}$, et al. Comparison of valsartan \&amlodepine on ambulatory \& morning BP in hypertensive patients. AM J Hypertens. 2004;17:1127.

11. Uno H, Ishikawa J, Hoshide S, Kabutoya T, Ishikawa $\mathrm{S}$, Shimada K, et al. effects of strict blood pressure control by a long acting calcium channel blocker on brain natriuretic peptide \& urinary albumin excretion rate in Japanese hypertensive patients. Hypetens Res. 2008;31:887-96.

12. Fogari R, Zoppi A, Malamani GD, Lusardi P, Destro M, Corradi L. Effects of Amlodipine vs Enalapril on Microalbuminuria in Hypertensive patients with Type II Diabetes. Clin Drug Investig. 1997;13(1):s42-9.

13. Chobanian AV, Bakris GL, Black HR, Cushman WC, Green LA, Izzo JL jr., et al. seventh report of Joint Natinal Committee on Prevention, Detection, Evaluation, \& Treatment of High blood pressure. Hypertension. 2003;42:1206-52

14. Wilson TW, Lacourcière Y, Barnes CC. The antihypertensive efficacy of losartan and amlodipine assessed with office and ambulatory blood pressure monitoring. Canadian Cozaar Hyzaar Amlodipine Trial Study Group. CMAJ. 1998;159(5):469-76.

15. Watanabe N, Kamei S, Ohkubo A, Yamanaka M, Ohsawa S, Makino K, et al. Urinary protein as measured with a pyrogallol red-molybdate complex, manually and in a Hitachi 726 automated analyzer. Clin Chem. 1986;32(8):1551-4.

16. Kalra S, Kalra B, Agrawal N. Combination therapy in hypertension: An update. Diabetol Metab Syndr. 2010;2(1):44.

17. Fukutomi M, Hoshide S, Eguchi K, Watanabe T, Shimada K, Kario K. Differential effects of strict blood pressure lowering by losartan/ hydrochlorothiazide combination therapy and highdose amlodipine monotherapy on microalbuminuria: the ALPHABET study. J Am Soc Hypertens. 2012;6(1):73-82.
18. Phillips RA, Kloner RA, Grimm RH Jr, Weinberger $M$. The effects of amlodipine compared to losartan in patients with mild to moderately severe hypertension. J Clin Hypertens (Greenwich). 2003;5(1):17-23.

19. Fernández-Andrade C, Russo D, Iversen B, Zucchelli P, Aranda P, Guerra L, et al. Comparison of losartan and amlodipine in renally impaired hypertensive patients. Kidney Int Suppl. 1998;68:S120-4.

20. Ruilope LM, Malacco E, Khder Y, Kandra A, Bönner G, Heintz D. Efficacy and tolerability of combination therapy with valsartan plus hydrochlorothiazide compared with amlodipine monotherapy in hypertensive patients with other cardiovascular risk factors: the VAST study. Clin Ther. 2005;27(5):57887.

21. Chung JW, Lee HY, Kim CH, Seung IW, Shin YW, Jeong $\mathrm{MH}$, Cho MC, Oh BH. Losartan/Hydrochlorothiazide fixed combination versus amlodipine monotherapy in korean patients with mild to moderate hypertension. Korean Circ J. 2009;39(4):151-6.

22. Dahlöf B, Lindholm LH, Carney S, Pentikäinen PJ, Ostergren J. Main results of the losartan versus amlodipine (LOA) study on drug tolerability and psychological general well-being. LOA Study Group. J Hypertens. 1997;15(11):1327-35.

23. Volpe M, Junren Z, Maxwell T, Rodriguez A, Gamboa R, Gomez-Fernandez P, et al. CDSP-944 Study Group. Comparison of the blood pressurelowering effects and tolerability of Losartan- and Amlodipine-based regimens in patients with isolated systolic hypertension. Clin Ther. 2003;25(5):146989.

24. Griffin KA, Bidani AK. Progression of renal disease: renoprotective specificity of renin-angiotensin system blockade. Clin J Am Soc Nephrol. 2006;1(5):105465 .

Cite this article as: Sawant SD, Chawre SM, Dudhal KS, Bansode AA. Evaluation of losartan plus hydrochlorothiazide combination therapy against amlodipine monotherapy in patients of hypertension. Int J Basic Clin Pharmacol 2019;8:2528-34. 